\title{
FEDERALISMO COOPERATIVO E GARANTIA DE PADRÃO DE QUALIDADE DO ENSINO: O CASO DOS ESTABELECIMENTOS DE EDUCAÇÃ̃O INFANTIL JURISDICIONADOS AO SISTEMA ESCOLAR DO ESTADO DE SÃO PAULO
}

\author{
Nina Beatriz Stocco Ranieri \\ Professora Doutora do Departamento de Direito do Estado \\ da Faculdade de Direito da Universidade de São Paulo
}

\begin{abstract}
Resumo:
Compete ao Estado garantir padrão de qualidade do ensino em todos os níveis educacionais. Como a organização da educação no Brasil acompanha a organização federativa, segue-se que o dever do Estado deve ser efetivado mediante descentralização normativa e executiva, exercida pela União, Estados, Distrito Federal e Municípios, de acordo com a repartição de competências, legislativas e materiais, promovida pela Constituição Federal e pela Lei de Diretrizes e Bases da Educação Nacional (Lei n. 9.394, de 20/12/96). O padrão de qualidade do ensino básico nas escolas públicas do Estado de São Paulo supõe prolessores qualificados cm sala de aula e em lunções de direção (art. 64 da LDB). Se o Conselho Nacional de Educação dispensa a autorização prévia para os cursos de especialização cm pedagogia, necessária para aferir tal qualidade, deixando de exercer sua Junção liscalizadora com rellexos e efeitos negativos para os demais sistemas de ensino, devem estes fazê-lo. Trata-se do exercício de poder-dever para os órgãos normativos dos sistemas de ensino afetados. O lundamento legal para tal aluação, nesses casos, radica-se nos arts. 208, VII e 18, da Constituição Federal c arts. $3^{\circ}$, IX; $9^{\circ}$, IX, c I0, I c V da LDB. A matéria é examinada a partir de consulta formulada pelo Conselho Estadual de Educação do Estado de São Paulo.
\end{abstract}

\begin{abstract}
:
It is up to the State to guarantee a high standard of education in all educational levels. Since the organization of education in Brazil follows the federal organization, it is the State's duty to check this, through normative and executive decentralization, exercised by the Union, States, Federal District and Municipalities, according to administrative, legislative and material jurisdictions promoted by the Federal Constitution and by the Lei de Diretrizes e Bases (Law of Directives and Bases) of National Education (LDB) (Law n. 9.394, of 12/20/ 96). The standard of quality for basic education in public schools of the State of São Paulo presupposes qualified teachers in the classrooms and management functions (art. 64 of the LDB). If the National Council of Education foregoes previous authorization for specialization courses in pedagogy, necessary to check the activity, not exerting its supervisory function, with reflexes and negative elfects for the other systems of education, these must carry it out. It is the exercise ol power/obligation affecting normative organs of the systems of education. The
\end{abstract}


Iegal principles for this activity, in this case, originates in arts. 208, VII and 18 of lhe Federal Constitution and arts. $3^{\text {rd }}$, IX; $9^{\text {Ith }}$ IX and 10 , I and V of the LDB. The subject is examined arising from a consultation formulated by the Conselho Estadual de Educação (State Education Council) ol the State of São Paulo.

Unitermos: Educação nacional; organização lederativa; federalismo cooperativo; competências; si stcmas de cnsino; princípios cducacionais; garantia de padrão de qualidade do ensino.

\section{A Consulta}

I. A E. Câmara de Ensino Superior do Conselho Estadual de Eclucação, por sua Presidente, formulou consulta acerca de matéria relacionada à garantia de padrão de qualidade nos estabelecimentos de educação básica jurisdicionados ao sistema escolar do Estado de São Paulo.

Tratava-se de analisar, do ponto de vista jurídico, uma das conclusões alçadas em proposta de indicação, que estabelecia orientações para o exercício das atividades previstas no art. 64 da Lei de Diretrizes e Bases da Educação (Lei no. 9.394/ 96), nos seguintes termos:

"2.1- Pelo exposto pode-se concluir que o exercício de atividades (cargo ou função) de administração (dirctor ou gestor de escola), plancjamento, inspeção, supervisão e orientação de educação básica jurisdicionadas ao sistema cscolar do Estado de São Paulo pode ser excreida por:

(...............................)

2.1.4- Portadores de certificados de conclusão de cursos de especialização, desde que destinados à formação de especialistas em cducação c aprovados previamente pelo Conselho Estadual de Educação."

Determina o citado art. 64 que " a formação de profissionais de educação par administração, planejamento, inspeção, supervisão c orientação educacional para a educação básica, será feita em cursos de graduação em Pedagogia ou $\mathrm{cm}$ nível de pós-graduação, a critério da instituição de ensino, garantida, nesta formação, a base comum nacional"

Considerando que os cursos de especialização constituem modalidade de pós-graduação (art. 44, III, da LDB) e que as instituições de ensino superior privadas que os ministram encontram-se liberadas de submeter-se à autorização, reconhecimento c renovação de reconhecimento, por força da Resolução CNE/CES n. 1, de 03/04/01 
(art. $6^{\circ}$ ), junto aos órgãos competentes do sistema de ensino federal, ao qual se submetem (art. 16, II, da LDB); entendeu o E. Conselho Estadual de Educação que deveria exereer o controle de qualidade nesses casos, em razão da "prolifercação de cursos de especialização não sujeitos à sua jurisdição, frequientemente de baixa qualidade, e do fato de o Conselho Nacional de Educação não mais exigir autorização prévia para a criação e o funcionamento dos mesmos."

Diante dessas circunstâncias, submetcu-nos a E. Câmara de Educação Supcrior os seguintes

Quesitos:

"1. Abrindo o CEE o exercício de atividades de administração (diretor ou gestor de escola), de planejamento, inspeção, supervisão e orientação de educação básica, jurisdicionados ao sistema escolar do Estado de São Paulo, a portadores de certilicados de conclusão de cursos de especialização destinados à formação de especialista $\mathrm{cm}$ educação, pode o mesmo Consclho estabelecer a condição de que releridos cursos sejam aprovados previamente pelo CEE, nos termos da Deliberação n. 09/98, excluindo-se os especialistas formados por instituições vinculadas ao sistema fedcral de ensino?"

"2. Em caso de resposta positiva, pode o CEE submeter cursos de especialização, não sujeitos à sua jurisdição, à sua aprovação, a pedido dos interessados, para cleito do excrcício das alividades acima descritas?"

$\mathrm{Bcm}$ examinadas as questões levantadas, loram as mesmas examinadas na seguinte conformidade: I) partindo da organização da educação nacional, são examinadas as competências da União c dos Estados e a dos respectivos sistemas de ensino; a seguir, (II) é analisado o princípio da garantia do padrão de qualidade do cnsino, de extração constitucional, que informa, obrigatoriamente, a atuação daqueles sistcmas; finalmente, (III) procura-se delimitar-sc o âmbito c os limites desta atuação no atendimento do referido princípio da garantia do padrão de qualidade.

I. A Organização da Educação Nacional.

As Compctências da União e dos Estados.

A Aluação dos Sistemas de Ensino.

1. A organização da educação no Brasil acompanha a organização lederativa do País, o que significa dizer que o dever do Estado com a educação scrá cletivado mediante descentralização normativa e executiva, exercida pela União, Estados, Distrito Federal e Municípios, de acordo com a repartição de competências, 
legislativas c materiais promovida pela Constituição Federal c pela Lei de Dirctrizes e Bases da Educação Nacional - LDB (Lei n. 9.394, de 20//2/96).

Conforme já nos manifestamos anteriormente,' o tema das compelências no Estado Federal é dos mais importantes, senão o fundamental.

Relaciona-se com a instiluição de um governo compatível com as exigências e necessidades da União, além de influir diretamente no equilíbrio do pacto federativo, determinando o grau de tensão entre poder central e as unidades periféricas, no que diz respeito a descentralização e controle (aspectos fundamentais na área da cducação $\mathrm{cm}$ face das disposições da Lei n. 9.394/96 que, mesmo assegurando ampla liberdade de conteúdo c forma no oferecimento, para todos os níveis de ensino, impõem um padrão de controlc sistemático e periódico das atividades públicas e privadas na área educacional,am nome da supremacia do interesse público em termos de qualidade).

Quanto mais ampla a compelência dos órgãos centrais, mais restrita scrá a dos órgãos periféricos, e maior o grau de centralização; inversamente, quanto maior a competência dos órgãos periléricos, menor a do órgão central, e maior o grau de descentralização.

A descentralização do poder estatal no federalismo supõe graus quantitativamente variáveis, determinados pela proporção relativa do número e da importância das normas centrais e locais na ordem jurídica. Resulta da combinação de critérios funcionais e espaciais, bem como de técnicas de repartição horizontal e vertical de competências que operam segundo os estágios hicrárquicos da ordem jurídica e quantidade de matérias a serem regulamentadas. A idéia subjacente é permitir que os dois níveis de estatalidade, o central e os periléricos, funcionem autônoma c concomitantemente.

No caso da educação, cabe à União legislar privativamente sobre dirctrizes e bases da educação nacional (cf. art. 23, XXIV) e concorrentemente com os Estados e o Distrito Federal, sobre normas gerais de educação, na forma do art. 24, IX c parágrafos, do que resulta a centralização legislativa da matéria, com a possibilidade de os Estados de os Estados suplementarem a matéria para atender a suas peculiaridades, apenas nesta última hipótese.

No plano dos encargos, que é o que nos interessa em face do teor da consulta, observa-se que o quadro de compctências lixado na Constituição de 1988 alual, de modo geral, em favor de competências concorrentes, apontando para um federalismo cooperativo mais preocupado com a colaboração dos entes federados do 
que com a sua separação e independência recíprocas. Há, efetivamente, descentralização c atuação $\mathrm{cm}$ regime de colaboração.

Para o federalismo cooperativo a coordenação das açōes é tão essencial quanıo a uniformização de certos interesses. Assim, toda a matéria que extravase o peculiar interesse de uma unidade perilérica porque é comum a todas ou porque, se particularizada num âmbito autônomo, engendraria conflitos ou dificuldades no intercâmbio nacional, constitui matéria principiológica. Vejamos.

2. Nota-sc, já da simples leitura do art. 205 da Constituição Federal, a caracıcrização da educação como encargo de todas as pessoas de direito público interno: "Art. 205-A educação, direito de todos e dever do Estado, será promovida e incentivada com a colaboração da sociedade, visando ao pleno desenvolvimento da pessoa, sen preparo para o exercício da cidadania e sua qualificação para o trabalho."

Trata-se, elelivamente, de responsabilidade comum da União, dos Estados, do Distrito Federal e dos Municípios, cujo conteúdo axiológico (o desenvolvimento da pessoa, seu preparo para a cidadania e sua qualificação para o trabalho) é corolário dos objelivos lundamentais da República, apontados no art. $3^{\circ}$ da Constituição Federal. ${ }^{2}$ Nesta tarefa também se congregam a família e a sociedade, sob ass normas da educação nacional, assegurada a atuação controladora do Poder Público.

A responsabilidade comum do Estado é reafirmada em outros dispositivos constitucionais, como o art. 208 (que define obrigações para efetivação do dever do Estado), ${ }^{3}$ c o art. 209, II (rclativamente à autorização e avaliação de qualidade das

2. "Art. 3"-Constituem objetivos findamentais da Repiblica Federativa do Brasil: I- construir uma sociedade live, justa e solidáriat: II- garamir o desentohimemonaciomal; III- erradicar a pobreza e a

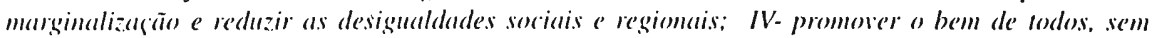

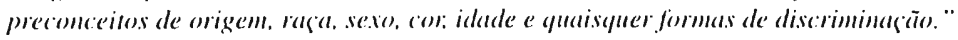

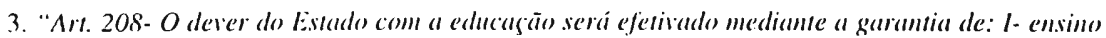
fundamentul obrigatorio e gratuito, assegurada. inchusive, sua oferta gratuita para todos os que näo

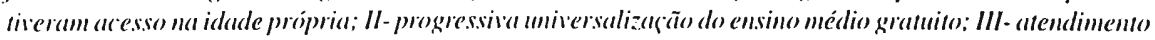
educacional especializado ass portadores de deficiências, preferencialmeme na rede regular de ensino: $I V$ - atendimenor em creche e pré-escola às criangas de zero a scis anos de idade; V- acesso ans níveis

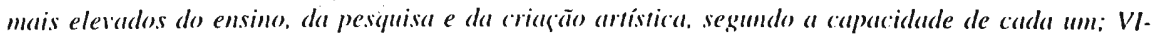
oferta de ensino noturno regular; adequado às condif̧öes do educando; VII- atendimento aro eductando, no ensino fundamental, atrarés de programas suplementares de material didático-escolar; transporte. alimentaşão e assistência à saúde.

$\$ 1^{\circ}$ - O acesso an ensino obrigatório e gratuito é direito público subjetivo.

$\$ 2^{\circ}$ - O não oferecimento do ensino obrigatório pelo Poder Páblico, ou sua oferta irregular, importa responsabilidade da autoridade competente.

$\$ 3^{\circ}$ - Compete ao Poder Pablico recensear os educandos no ensino finddamental, fazer-lhes a chamada e zelar: junno ans pais on responsciveis, pela frequiência à escola." (gn) 
instituições privadas de ensino pelo Poder Público) ${ }^{4}$ a par da indicação de responsabilidades prioritárias, mas não exclusivas, por nível de ensino, para cada csfera de governo, expressa nos parágrafos $2^{\circ} \mathrm{e} 3^{\circ}$ do art. 211.5

No mais, a atuação do Estado desenvolve-se de acordo com mecanismos próprios do lederalismo cooperativo, tais como a exigência de colaboração entre os entes lederados na organização dos seus sistemas de ensino (art. 211, "caput"); a atribuição de funções redistributivas e supletivas à União, para garantir equalização de oportunidades educacionais e padrão mínimo de qualidade de ensino (art. $\left.211, \$ 1^{\circ}\right)^{n}$; a integração das ações do Poder Público, que conduzam à melhoria da qualidade de ensino, por via do Plano Nacional de Educação (art. 214, III) e, especialmente, a conjugação de esforços para universalização c linanciamento ao ensino fundamental (art. 208, I c art. 60 do Ato das Disposiçcôcs Constitucionais Transitórias), c progressiva universalização do ensino médio (art. 208, II).

Todas cssas previsões, enlïn, reclamam e evidenciam a necessidade de organização dos respectivos sistemas de ensino $\mathrm{cm}$ regime de colaboração, especialmente no que diz respeito à educaç̧ão lundamental e média, componentes da educação básica, conlorme dispõe o art. 21, I, da Lei de Diretrizes e Bases LDB $^{7}$ o que não os exime, por evidente, do cometimento de obrigą̧ões próprias.

3. Atuação dos sistemas de ensino se laz, portanto, em dois planos distintos, reciprocamente condicionados $\mathrm{c}$ integrados $\mathrm{cm}$ razão da matéria educacional

\footnotetext{
4. "Art. 209 - O ensino é livre à iniciativa privada, atendidas as seguintes condições:

1 -

II- aunorizașão e araliasão de qualidade pelo Poder Público." (gn)

5. "Art. $211-$
}

$\$ 2^{\circ}$ Os Municípios atuarão prioritariamente no ensino fundamental e na educação infantil.

$\$ 3^{\circ}$ Os Estados e Distrito Federal atuarão prioritariamente no ensino fundamental e médio."

$\$ 4^{\circ} \mathrm{Na}$ organização dos scus sistemas de ensino, os Estados e os Municípios definirio formas de colahoração, de modo a assegurar a universalização do ensino obrigatório."

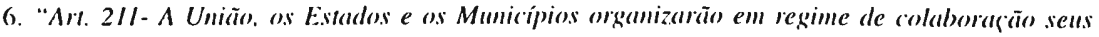
sistemas de ensimo.

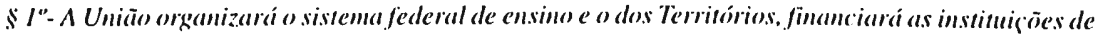
ensino piblicas federais e exerceri, em matéria educacional, funsäor redismibutiva e suplestivo, de forma a garamir equalizasaion de oportunidades educ acionais e padräo minimo de qualidade do ensino medianne assistência técnica e financeira aos Estadoss, an Distrito Federal e aos Municípios."

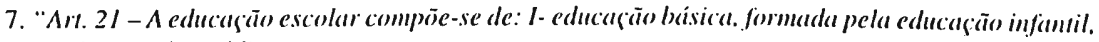
ensino fiundamental e médio: 
c da autonomia que lhes é garantida pela Constituição Federal: no da colaboração e no das competências prioritárias próprias.

Tanto num quanto noutro, poderão eleger formas de atuação, de organização e gestão dos clementos que os compõem.

$E$ isto porque sua organização acompanha a organização políticoadministrativa da República (cf. art. 18, "caput”, da Constituição Federal) , aplicandose-lhes, por simetria o princípio federativo da descentralização normativa e executiva.

A autonomia dos sistemas de ensino não signilica independência nem soberania, porque se encontra condicionada por normas legais e constitucionais e restrita a áreas previamente delimitadas, mas lhes garante ampla margem de liberdade para eleger os lins c os meios que julgar mais adequados à consecução das metas educacionais em seu território."

Dentre os diversos condicionamentos impostos à autonomia dos sistemas de ensino pelo ordenamento jurídico, devem ser destacados, em razão da matéria, o constante do inciso VII, do art. 206 da Constiluição Federal, referente à garantia de padrão de qualidade do ensino, princípio inlormador da atividade educacional, ${ }^{10}$ e os dos arts. $9^{\circ}, 10,16 \mathrm{c} 17$ da LDB, relativos ao âmbito e às competencias dos sistemas de ensino.

Com relação a esıes últimos, importa assinalar que todas as instituições de educação superior, criadas e mantidas pela iniciativa privada estão comprecndiclas no sistema lederal de educação" , aí incluídas as que ministram cursos de especialização,

8. "Art. 18- A organizasũo político-administrativa do Brasil compreende a Uniãos, os Estados, o

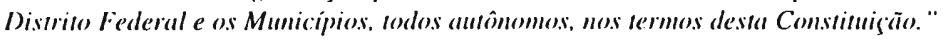

9. Conforme já tive oportunidade de me manifestar na doutrina, o conceito de autonomia no Dircito Público é abstrato, imaterial: designa a possibilidade de dirę̧ão própria consentida por ordenamenoo superior e manifestada por normas exclusivas. Encerra poder político, de natureza pública. É também poder funcional com finalidade especílica: destina-se a operacionalizar o cometimento ideal de tarefias públicas, razão pela qual sofre controle. Constitui, enfim, poder funcional derivado, exercitável nos limites determinados pelo ordenamento jurídico, visando à melhor realização de tarefas públicas. (Autonomia Universitária, São Paulo, EDUSP, 1994: 26-7).

10. "Art. 206 - O ensino será ministrado com base nos seguintes principios:

VII- garamia do padrāo de clualidade.

11. O sistema federal de ensino, conforme dispöe o art. 16 da LDB, compöe-se (I) das instituiçöes de cusino mantidas pela União, (II) pelas instituições de educação superior criadas e mantidas pela iniciativa privadas ma nítidas pela União, (III) pelos órgãos federais de educaçāo. Os sistemas estaduais, por sua vez, (I) pelas instituiçōes de ensino mantidas pélo poder público estadual e do Distrito Federal, (II) pelas instituições de educação superior mantidas pelo Poder Público municipal, (III) pelas instituições de ensino fundamental e médio criadas e mantidas pela iniciativa privada: (IV) pelos órgãos de educação estaduais é do Distrito Federal, respectivamente (cf. ar. 17). 
por força do art. 44, III, da LDB ${ }^{12}$; e que competc à União autorizá-los, reconhecê-los, credenciá-los, supervisioná-los e avaliá-los, conforme determina o inciso IX, do art. $9^{\circ}$ da LDB. ${ }^{13}$

4. Note-se que a LDB, ao dispor acerca dos elementos que integram sistemas de ensino, não atendeu ao princípio da descentralização normativa e executiva própria da organização federativa, criando um aparente obstáculo à garantia do padrão de qualidade pelos Estados, uma vez que os excluiria do processo de avaliação dos estabelecimentos privados de ensino superior localizados em seus territórios, com relcvantes consequiências e implicações práticas, como se observa na consulta trazida a lume pela E. Câmara de Educação Superior.

O obstáculo é de fato aparente, não prosperando em face do condicionamento da atividade dos sistemas de ensino pelo referido princípio da garantia do padrão de qualidade e de outras razões de ordem constitucional, como se passa a demonstrar.

II. A Garantia do Padrão de Qualidade como Princípio Informador da Educação Nacional.

5. A Constituição Federal de 1988 consagrou a garantia de padrão de qualidade do ensino como um dos princípios informadores da atividade educacional, ao lado da valorização dos prolissionais do ensino, da liberdade de aprender, ensinar, pesquisar e divulgar o pensamento, do pluralismo de idéias e concepções pedagógicas, da coexistência de instituições públicas e privadas de ensino, dentre outros.

Como visto, na mecânica do federalismo cooperativo a coordenação de ações é tão essencial quanto a uniformização de certos interesses; em conseqüência, detcrminadas matérias, de relevância nacional, têm caráter principiológico, cstendendose sua observância obrigatória e indistintamente a todas as pessoas de Direito Público envolvidas.

É o que ocorre com o princípio de garantia de qualidade do ensino, de especial relevância na dinâmica constitucional, dados os seus desdobramentos em relação à cl'ctivação dos objetivos fundamentais da República.

Com efeito, uma das regras fundamentais da hermenêutica constitucional é a da unidade da Constituição, aquela que obriga o intérprete a vê-la como um

12. "Art. 44- A educașōo superior abrangerá os seguintes cursos e programas: (...) III- de posgraduação, compreendendo programas de mestrado e doutorado, cursos de especialização, aperfeiconmento e outros, .......".

13. "Art. 9" - A Uniāo incumbir-se-á de: (...) IX - antorizar; reconhecer; credenciar; supervisionar $e$ avaliar; respectivamente, os cursos das instituições de educaçäo superior e os estabelecimentos do seu sistema de ensino." 
"articulado de sentido" (na precisa expressão de Tércio Sampaio Ferraz Jr., Interpretação c Estudos da Constituição de 1988, São Paulo, Atlas, 1990: 86), orientado por uma lógica hicrárquica que se manifesta por meio de disposições coordenadas e interrelacionadas, reciprocamente condicionadas em escalões sucessivos.

Dentro desta lógica, que comprecnde princípios c regras, são os princípios constitucionais os vetores que dão sentido ao conjunto do ordenamento jurídico, as prescrições genéricas que se especificam em regras, "in casu”, os contidos no já citado art. $3^{\circ}$, da Constiluição Federal.

Sendo mandamentos nucleares de um sistema, ${ }^{1+}$ expressão maior da normatividade que lundamenta a organização do poder, ${ }^{15}$ possuem os princípios a dimensão do peso ou importância, dimensão que nãó é própria das regras jurídicas.

É dentro dessa dimensão valoraliva que em cada caso se armam diversos jogos de princípios, de sorte que diversas soluções e decisões, em diversas situações, podem ser alcançadas; sendo certo que tanto o aplicador quanto o intérprete do dircito, ao comporem tais jogos de princípios, atuam sob o impacto de valores ideológicos. ${ }^{16}$

Estabelece-se assim uma relação de instrumentalidade entre os princípios constitucionais e o exercício dos poderes públicos, que possibilita sua aplicação a uma sćric de necessidades de conteúdo político e não-só jurídico. Nestas circunstâncias, alćm da função de direcionamento, exercem os princípios funções corretivas, proporcionando ao Poder Público a identificação de medidas que atuem em prol de determinadas metas sociais.

A cxegese dos princípios admite, pois, peso e importância diferentes quanto ao seu grau de legitimidade, como é o caso do controle de qualidade na consulta

14. Na clíssica lição de Celso Antonio Bandeira de Mello: "Princípio é, por definiçăo, mandamento muclear de um sistema, verdadeiro alicerce dele, disposisgão fundamental que se irradia sobre diferentes: normas compondo-llie o expirito e senvindo de critério para sua exata comprecensão e inteligência, exatamente por definir a lógica e a racionalidade do sistema normativo, no que the comfere a tônica e the da sentido harmônico (...)." (Natureza e Regime Jurídico das Autarquias, São Paulo, Revista dos Tribunais, 1968:230).

15. Paulo Bonavides acentua o caráter valorativo dos princípios: "Näo há distingüo entre princípios e normas, os principios são dotados de normatividade. as normas compreendem regras e princípios, a

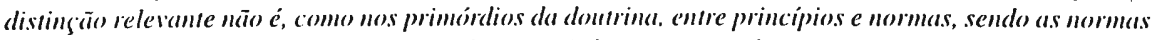

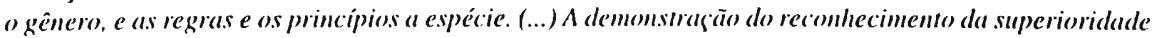
e hegemonia dos princípios na pirâmide normativa; a supremacia que não é unicamente formal, mas sobretudo material, e apenas possivel na medida em que os principios são compreendidos e equiparados e ué mesmo confiundidos com os valores, sendo, na ordem constitucional dos ordenamentos juridicoss. a expressão mais alta da normatividade que fundamenta a organizas āo do poder:" (Curso de Dircito Constitucional, São Paulo, Malheiros, 1994:259).

16. Cf. Eros Roberto Grau, A Ordem Ecomômica na Comstituição de 1988, São Paulo, Malhciros, $3^{2}$.ed., 1997. 
"sub examine" uma vez que no oferecimento da educação, o princípio informador do dever cstatal Estado, como já apontado, decorre de princípio dito fundamental, expresso telcologicamente no art. 3" da Constituição Federal.

6. Assim, considerando-se que do ângulo da hermenêutica constitucional tais princípios não admitem interpretação restritival, desdobrando-se numa sćric de direitos e deveres, a garantia de padrão de qualidade é de observância obrigatória, cm qualquer circunstância, para qualquer sistema de ensino; o que é relorçado com a previsão do art. $3^{\circ}$ IX da LDB, que o repete.

A mesma conclusão se evidencia sob o ângulo do federalismo cooperativo, considerando-se especialmente o teor do art. 211 , relativamente à exigência de organização dos sistemas de ensino, federal, estaduais e municipais, em regime de colaboração; e do princípio lederalivo da descentralização normativa e executiva, expresso no art. 18, que assegura aos Estados competência para exercê-la.

E ainda cm lace do "caput" do art. 37, da Constituição Federal, reforçáse a conclusão, ante a exigência de que a Administração Pública, direta e indireta, de qualquer dos Poderes da União, dos Estados, do Distrito Federal e dos Municípios, atenda ao princípio da eficiência.

Entende a melhor doutrina, que este princípio corresponde ao dever da boa administração, que supõe e requer que todo agente público realize suas atribuições com presteza, perfeição e rendimento funcional (Hely Lopes Mcirclles, Dircito Administrativo Brasilciro, São Paulo, Malhciros, 1996: 90-1). Volta-sc, portanto, ao melhor desempenho de funções públicas, para alcance dos melhores resultados, pois o que importa aos cidadãos e que os scrviços e as funções públicas sejam prestadas adequadamente (cli. Maria Sylvia Zanella Di Pictro, Dircito Administrativo, São Paulo, Atlas, 2()() : 84).

Ora, como pode ser eliciente a educação básica sem controle da qualidade dos cursos de especialização para formação dos professores que nela atuam?

O padrão de qualidade do ensino básico nas escolas públicas do Estado de São Paulo supõe professores qualificados $\mathrm{cm}$ sala de aula e $\mathrm{em}$ funções de direção. É o que exige o art. 64 da Lei de Diretrizes e Bases. Sc o Consclho Nacional de Educação dispensa a autorização prévia para os cursos de especialização cm pedagogia, deixando de exercer sua função liscalizadora com rellexos e eleitos negativos para os demais sistemas de ensino, devem estes lazê-lo.

Trata-se, na hipótese, do excrécio de verdadeiro poder-dever para os órgãos normativos dos sistemas de ensino aletados, corolário do dever do Estado com 
a cducação c que neste caso se sobrepõe (e extrapola) aos limites da regra do art. $9^{\circ}$, IX, da LDB, porque se cuida de princípio educacional, de obscrvância comum c obrigatória a todos os entes lederados. ${ }^{17}$

Com efeito, a autonomia dos sistemas de ensino, de extração legal c constitucional, não se compadece com omissões no campo das competencias cducacionais comuns. À ausência de medidas que assegurem a colaboração entre os sistemas de ensino, especialmente no que diz respeito à eletivação dos princípios informadores da atividade educacional, permite aquela a adoção de medida corretiva, que atuem em prol da meta nacional.

7. Nessas circunstâncias, qual o âmbito c os limites da atuação do sistema estadual de ensino na garantia do padrão de qualidade'? Mais especilicamente, quaị as medidas que pode adotar, dentro da legalidade, para garantir o controle das variáveis que interlerem qualitativamente na atividade educacional sob sua responsabilidade?

III. A Efetivação do Princípio da Garantia do Padrão de Qualidade pelos Sistemas de Ensino

8. Como visto, a LDB impõe limites à atuação autônoma dos sistemas de ensino, limites estes expressos em vários dispositivos, dentre eles nos arts. $9^{\circ}: 10$, $16 \mathrm{e} 17$.

Tais limites, porém, podem vir a ser relativizados pelos princípios informadores da atividade educacional, sempre que os objetivos teleológicos da educação nacional possam sofrer lesão ou ameaça de lesão, potencial ou efetiva.

Outras razões de ordem constitucional e legal levam à mesma conclusão.

No plano constitucional, conforme já me manilestei anteriormente, ${ }^{1 \times}$ ainda que a LDB tenha reservado à União a maior parte das atribuições normativas relativas à educação superior, essas funções não podem a extrapolar os limites da organização federativa do País, impedindo a observância dos princípios informadores da educação pelos demais entes federados, pelas seguintes razões:

17. Diz Carmén Lúcia Antunes Rocha (República e Federação no Brasil, Traços Constitucionais da Organizaçāo Política Brasileira, Belo Horizonte, Del Rey, 1997:253) que o que marca as competências comuns à a "difusüo dos interesses que se encontram subjacentes e que determinam um condominio de atuaräés. Nenhuma das entidades é titular exclusira, superior ou desigual das competências. Näo se dá a exclusividade da responsabilidade de uma delas nem (e muito menos) a omissão possivel dessa responsabilidade por qualquer delas."

18. Cf. Educação Superior, Direito e Estado na Lei de Diretrizes e Bases - Lei n. 9.394/96; São Paulo, EDUSP, 2000. 
a) a Constituição Federal, ao consagrar a federação brasilcira, garantiu expressamente em seu art. 18 a autonomia da União, dos Estados, Distrito Federal e dos Municípios, cm termos político-administrativos. Assim é que, no campo da educação, reservou à União a competência para legislar genericamente, garantindo aos Estados a normatização das peculiaridades regionais (cf. art. 24). Claro está, por conscguinte, que em face desta estrutura não é viável que a lei ordinária, ainda que de alcance nacional, determine, ao arrepio da organização política, escapar ao poder dos Estados a regulamentação ou o controle de qualidade das instituições privadas de ensino superior sediadas em seu território, como o faz a Lei de Diretrizes e Bases;

b) reforça-se a conclusão ante os termos do art. 209 da Constiluição Federal, que, ao impor ao Poder Público a autorização e a avaliação de qualidade das instituições płivadas de ensino, não distinguiu entre os diversos niveis de governo, do que decorre o lundamento da compelência dos Estados em relação às instituições privadas de ensino superior (como de resto ocorre em relação aos demais níveis de ensino), sem que as tenha isentado do cumprimento das normas gerais de educação, nem eximido os Estados, o Distrito Federal e os Municípios, e a própria União, de organizarem scus sistemas de ensino cm regime de colaboração (art. 211, "caput").

Logo, com fundamento nos arts. 18, 205, 206, VII, 209, II c 211 da Constituição Federal; bem como no art. 242 da Constituição do Estado de São Paulo, que qualilica o Conselho Estadual de Educação como órgão normativo, consultivo c deliberativo do sistema de ensino no Estado de São Paulo e nos arts. $3^{\circ}$, VII; 10, I e V; e 64 da LDB, deduz-se claramente a competência constitucional e legal do CEE para promover a qualidade de ensino $\mathrm{cm}$ seu território de jurisdição, para salvaguarda da qualidade da sua rede de cducação básica (e não-só cm relação a csta, a rigor).

9. Há um outro aspecto a ser Icvado em consideração no concernente a potenciais lesões aos objetivos telcológicos da educação nacional pelos sistemas de ensino.

Diz respeito à ilegalidade do art. $6^{\circ}$ da Resolução CNE/CES n. 1/01, no aspecto ora examinado, por desvio de poder ${ }^{14}$ posto desatender à finalidade do inciso IX, do art. $9^{\circ}$ da LDB, exorbitando os limites da função normativa do Poder Exccutivo.

Determina o dispositivo: "Art. $6^{\circ}$ Os cursos de pós-graduação latosensu oferecidos por instituições de ensino superior ou por instituições especialmente

19. O desvio de poder encontra-se definido na Lei n. 4.717/65. como o vicio pelo qual "o agente pratica o ato risando am fim diverso datuele previsto, explicita ou implicitamente. na regra de rompetência. 
credenciadas para atuarem nesse nível educacional, independem de autorização, reconhecimento e renovação de reconhecimento e devem atender ao disposto nesta Resolução." (gn)

No Direito brasileiro, o exercício do poder regulamentar está vinculado às definições decorrentes da lei, não podendo modificar ou ab-rogar as normas originárias, estatuídas pelo Legislativo, nem ultrapassar os lindes da lei que regulamenta. Este é o sentido da expressão fiel execução da lei, prevista no art. 84, IV da Constituição Federal, fundamento genérico do poder regulamentar, reiterado no art. 87,II.

O sistema federal, "in casu", extrapolou tais limites, ao liberar de controle os cursos de especialização. Em verdade, a citada Resolução nega o que a lei determina, em franco atentado ao princípio da legalidade, expresso no art. $5^{\circ}$. II e no art. 37, "caput" para a Administração Pública.

Ora, se a LDB incumbe a União de autorizar e reconhecer os cursos de especialização, conforme o art. $9^{\circ}$, IX, "ex vi" do art. 44, II, como poderia o Conselho Nacional de Educação desonerá-la?

Ainda que no art. $7^{\circ}$ determine que tais cursos ficam sujeitos à supervisão dos órgãos competentes quando do recredenciamento da instituição e, no art. $8^{\circ}$, thes imponha a obrigação de fornecer informações sempre que solicitadas, a posterior supervisão e o eventual fornecimento de documentos não elidem a obrigação legal, nem suprem o controle de qualidade como o comprovam as situações fáticas relatadas pela E. Câmara de Ensino Superior do CEE.

Essas situações, em verdade, expõem com clareza a rationale que congrega o princípio da garantia do padrão de qualidade às exigências do art. $9^{\circ}$, IX e do art. 64 da $\mathrm{LDB}^{20}$, no regime jurídico da educação, que impõe a formação dos profissionais da educação em cursos de Pedagogia, necessariamente, no nível de graduação ou no de pós-graduação, dadas suas implicações no desenvolvimento nacional.

Nula, portanto, a previsão, por afronta aos dispositivos constitucionais invocados, devendo o Conselho Nacional de Educação rever seu próprio ato, anulandoo, com fundamento no poder de autotutela da Administração, consagrado pelo Supremo Tribunal Federal nas Súmulas ns. 346 e 473.21

20. Observa-se a mesma idéia no art. 70, I, da LDB, no que se refere à aplicação de recursos públicos na remuneração e aperfeiçoamento dos profissionais da educação.

21. Súmula no 346: "A Administração Pública pode declarar a nulidade dos seus próprios atos." Súmula 473: "A Administração pode anular seus próprios atos, quando eivados de vícios que os tornem ilegais, porque deles não se originam direitos, ou revogá-los por motivos de conveniência ou oportunidade, respeitados os direitos adquiridos e ressalvada, em todos os casos, a apreciaçāo judicial. ' 
Essa situação, enquanto não superada no plano dos fatos, pelo efetivo controle qualitativo dos cursos de especialização, também enseja o alargamento dos limites de atuação dos demais sistemas de ensino para promover a garantia do padrão de qualidade, inclusive sob o ângulo do regime de colaboração.

10. Diante de todo o exposto, considerando-se que é dever dos sistemas de ensino garantir padrão de qualidade do ensino e atuar em regime de colaboração; que a União dispensa a avaliação dos cursos de especialização sob sua jurisdição, omitindo-se quanto ao controle dos mesmos, conforme consta da Resolução CNE/ CES n. 1/2001; que aos Estados cabe, de acordo com os incisos I e V, do art. 10 da LDB, baixar normas complementares para o seu sistema de ensino, visando organizar, manter e desenvolver os órgãos e instituições dos seus sistemas de ensino; nada obsta a nosso ver, do ponto de vista legal, a atuação do Conselho Estadual de Educação no sentido de exigir que referidos cursos sejam previamente aprovados pelo Colegiado, nos tcrmos da Deliberação CEE n. 9/98, para fïm de atendimento do art. 64 da LDB, cm relação à rede de educação básica estadual.

Em apoio à afirmação, veja-se a melhor doutrina:

Miguel Reale ("in" Questões de Direito, São Paulo, Sugestões Literárias, 1981:96-9), ao distinguir entre sistema federal e sistema estadual de ensino, assevera que sistema “(...) não se refere a um conjunto autônomo de idéias gerais diretoras ou ordenadoras do ensino, mas sim ao programa autônomo de atualização atribuído à União e aos Estados para tornarem efetivas as diretrizes e bases da educação nacional, segundo critérios e modelos próprios, na esfera das respectivas competências."

"Tudo somado, cada Estado organiza o seu sistema de ensino com autonomia, sendo-lhe lícito eleger os fins particulares e os meios que julgar mais adequados à consecução do Plano Nacional de Educação no âmbito do seu território, e até mesmo estabelecer objetivos especiais de ensino, desde que não conflitem com os predeterminados pela legislação federal eminente."

E mais: “(...) saliento que na idéia de sistema em geral se inclui a matéria pertinente à sua autotutela, isto é, o poder de fiscalização, o que decorre da idéiamatriz que anima o sistema como tal: a idéia de autonomia, nos limites traçados pela lei géral de diretrizes e bases, a qual, pelo visto, não pode esvaziar o sistema estadual do que é o próprio."

No mesmo sentido, propugnando que a lei brasileira, constitucional $\mathrm{c}$ ordinária, consagrou a organização federativa e a autonomia dos sistemas de ensino para atendimento das necessidades educacionais da União, dos Estados e dos 
Municípios, sem descuidar do regime de colaboração, veja-se Esther de Figueiredo Ferraz ("Os Sistemas de Ensino Federal e Local e as Respectivas Esferas de Competência” “in” Estudos em Homenagem a Vicente Ráo, Péricles Prade (org.), São Paulo, Ed. Resenha Universitária, 1976: 165-89); e Edivaldo Boaventura (A Educação Brasileira e o Direito, Salvador, Ed. Ciências Jurídicas, 1997), lembrando o autor que são, justamente, as decisões dos Conselhos de Educação que marcam a dilierença entre os procedimentos da União, dos Estados federados e dos Municípios, formando-se, em torno de cada uma dessas esferas políticas, um sistema de normas $\mathrm{e}$ instituições educacionais.

A organização federativa dos sistemas de ensino e sua conseqüente autonomia, também têm sido reafirmadas pelos Tribunais:

“Os Estados e Municípios, nos termos da atual Constituição, têm autonomia para organizar e gerir o seu sistema de ensino, não exercendo, pois, na hipótese, atividade delegada do poder federal." (STJ; I". Seção; v.u.; Conflito de Competência n. 18.659/MG [96/0072846-I]; DJ de 14/04/97). ${ }^{22}$

"Ao estabelecer que os sistemas de ensino devem fixar a remuneração dos professores e especialistas, tendo em vista a maior qualificação, sem distinção do gran escolar em que atuem, o mencionado dispositivo legal, que tem caráter de lei nacional, não quis referir uma qualificação qualquer, mas, sim, a exigida pelas leis locais, para os diversos níveis da respectiva categoria funcional, sem distinguir, é claro, v.g., o ensino fundamental de pré-escolar.

Do contrário, configurar-se-ia violação à autonomia, assegurada aos municípios, no art. 211 da carta de 1988 (art. 177 da EC/I/69), para organizarem os seus sistemas de ensino" (STJ; 2". Turma; v.u.; Recurso Especial n. 7723/SP; DJ de 03/06/9I).

"O Estado tem autonomia para organizar e gerir o seu sistema de ensino, nos termos do art. 211 da Constituição Federal" (STJ; I"Seção; v.u.; Conflito de Competência n. 2600/SP [9I/0023977-1]; DJ de 01/03/93) 2.1

11. Código de Educação do Estado de São Paulo, baixado pela Lei n. 10.125, de 4/6/68, vai, acertadamente, na mesma direção.

22. Idêntica emnenta consta de diversos julgados do Superior Tribunal de Justiça, em matéria análoga, dentre estes: Conflitos de competência n. 10.567/MG, 1ª Seção, v.u., DJ de 10/10/94; no 94/8/GO, $1^{2}$ Seção, DJ de I2/09/94; etc).

23. Idem, nos seguintes julgados: Recurso Especial n. 2.307I/PR, $2^{\text {a }}$ Turma, DJ de 12/06/95; Conflitos de Competência n. 8. 105/SP, $1^{2}$ Seção, v.u., DJ de 12/12/94; n. I.0567/MG, Iª Seção, DJ de 10/I0/94; n. 18659/MG, I’ Seção, DJ de I4/04/97; n. 941 8/GO, lª Seção, DJ de 12/09/94; n. 2672/PR, I" Seção, DJ de $01 / 03 / 93$ etc.). 
Define o sistema estadual de ensino como "o conjunto de normas que disciplinam, em seus vários aspectos, o processo educativo desenvolvido no Estado de São Paulo..." (cf. art. $9^{\circ}$ ); sendo que a rede de escolas, estaduais e municipais e particulares, existentes no território do Estado de São Paulo, vincula-se ao sistema cstadual de educação (cf. art. 10).

Ainda que baixado antes da Constituição de 1988 e da atual LDB, o relerido Código de Educação não ofende nem uma nem outra, porquanto há de se entender a vinculação dessas escolas em nome da integração, organização e gestão de todo o sistema de ensino, sem prejuízo da atuação do sistema federal em relação às instituições privadas de ensino superior.

Este foi o entendimento do Conselho Estadual de Educação do Estado de São Paulo, na Indicação n. 02/92, aprovada pelo Conselho Pleno em 01/04/92 (DOE de 09/04/92, Seção I, pp. 27-8), ao concluir que na atual Constituição Federal “(...) o significado da expressão 'sistema de ensino' tende mais a indicar um conjunto de normas do que um conjunto ou rede de instituições educacionais ou ambas as coisas englobadamente" A discussão se fez a propósito do pleito do CEE de inclusão, no sistema estadual, das instituições privadas de ensino superior localizadas no Estado de São Paulo, para fins de avaliação e controle, condições sem as quais não se faz possível a formulação e o êxito de uma política estadual exeqüível e realista, na medida em que loge ao controle do Estado o conjunto dos fatores que interferem na qualidade do ensino público fundamental c médio.

O tema não é novo e deve ser enlirentado, como ora o faz a E. Câmara de Ensino Superior, para garantia do padrão de qualidade do ensino.

12. A par das razões já apontadas, milita a favor da ampliação do controle do Conselho Estadual de Educação, na direção apontada, o próprio regime jurídico da educação nacional, tal como previsto na Lei de Diretrizes e Bases; regime que se submete ao Direito Administrativo e do qual, dadas suas características, resulta uma disciplina normativa peculiar, que se delineia em função da natureza pública da educação c da supremacia do interesse público sobre o particular.

Decorrem desse tratamento importantes conseqüências de ordem prática, dentre clas, no que concerne à matéria tratada:

a) na esfera pública, a especificidade dos princípios constitucionais que informam o desenvolvimento das atividades educacionais permite tratamento jurídico menos rígido das formas e processos (exemplo paradigmático é o da garantia do padrão de qualidade do ensino, ora examinado); 
b) diversamente, na esfera privada, a natureza pública da atividade cducacional determina a derrogação parcial de prerrogativas inerentes ao regime privatístico por normas de Dircito Público, dada a prevalência da finalidade pública sobre o interesse particular (como ocorre em relação às instituições privadas de ensino superior, submetidas que estão às normas gerais de educação).

A propósito, faço referência a observações já aduzidas anteriormente, ${ }^{24}$ tendo então apontado, no que concerne à esfera pública, que parece haver um alargamento do princípio da legalidade em direção ao "princípio da juridicidade" É dizcr, scm abrir mão do princípio da precedência da lei (que impede que a Administração atue "contra legem") nem do da reserva da lei (que impede que a Administração se conduza "praeter legem"), a "intensidade" da subordinação à lei se dá em dilerentes graus, consoante as matérias que cstão cm causa, havendo como que uma "elasticidade do vínculo de subordinação", que permite que a lei, em cerlas situações, apenas enuncie princípios gerais c, noutros casos, desça a pormenores. Conclui, portanto, que a relação de subordinação da Administração Pública à lei caracteriza-se, hoje, pela inexistência de quaisquer fórmulas rígidas.

Esta é a posição de Maria João Estorninho ("A Fuga para o Direito Privado: contributo para o estudo da actividade de direito privado da Administração Pública" Coimbra: Almedina, 1996) e de Charles Eisenmann ("O Direito Adıninistrativo e o Princípio da Legalidade" in Revista de Direito Administrativo, Rio de Janciro, Fundação Gctúlio Vargas, 1959, 56:47-70), no que respcita à aplicação do princípio da legalidade à atuação da Administração, por meio de uma relação de compalibilidade expressa na exigência de não-contradição à legislação, mais ampla do que a exigência de não-contrariedade da lei.

É o que demonstra, v.g., a introdução do princípio da eficiência dentre os princípios informadores da Administração Pública. Associado ao princípio da razoabilidade, permite interpretações mais substanciais e menos formais do regime jurídico administrativo, como se verifica na área educacional. Esta possibilidade nada mais implica senão a reinterpretação do ordenamento jurídico público, a partir dos princípios constitucionais c dos valores que os informam. ${ }^{25}$

24. Cf. Educação Superior, Direito e Estado, pp. 252 e ss.

25. Alirma Niklas Luhmann (Sociologia do Dircito II, Rio de Janciro, Tempo Brasileiro, 1985: 16.3. 4) que "(...) a contimuidade do desemohrimento näo depende da fidelidade nommativa do Direito positivo com referência a pressupostos suprapositivos de expectativas humanas globais, mas sim de capacidade de soluciomamento de problemas que, enquanto capacidade de análise e decisão, de reestruturasano assimilativa e de adaptugăo de programas, teraĩo de ser inseridos no sistema juridico tanto em termoss 
Em relação à esfera privada, a ampliação quantitativa da capacidade normativa do Executivo e o alargamento do princípio da legalidade, no sentido acima apontado, indica, simetricamente, uma alteração qualitativa das relações da Administração com os particulares, com inevitável diminuição do campo das situações c dircitos subjetivos. ${ }^{26}$

Mas até que ponto o interesse público deve ser considerado como clemento justificador de toda e qualquer intervenção do Poder Público na esfera privada, no campo educacional?

Se o interesse público é indissociável da atividade educacional, dada a sua conformação constitucional (arts. 205 e 209), não há margem de dúvida acerca da natureza principiológica e informadora daquele, nestes casos. Entretanto, ainda que a noção de "interesse público" seja imprecisa, a garantia do particular não se desvincula do fato de não haver interesse público a cargo do Poder Público a não ser os que a lei defina, expressa ou implicitamente ${ }^{27}$, que é o que ocorre com o princípio da garantia do padrão de qualidade do enşino, expresso no arl. 208, VII da Constituição Federal e no art. $3^{\circ}$, IX, da LDB.

Não há, portanto, na possível atividade controladora do Conselho Estadual de Educação, relativamente à avaliação de qualidade de cursos de cspecialização em Pedagogia não-sujeitos à sua jurisdição, qualquer ofensa a direito subjetivo dos particulares, pelas razões de direito apontadas.

\section{Conclusões}

13. O dever do Estado com a educação constitui responsabilidade comum da União, dos Estados, do Distrito Federal e dos Municípios; scu conteúdo axiológico (o desenvolvimento da pessoa, seu preparo para a cidadania e sua qualificação para o (rabalho) é corolário dos objetivos fundamentais da República, apontados no art. $3^{\circ}$ da Constituição Federal.

categoriais como institucionais. Nesses termos, o Direito não mais vige em razão de sua invariabilidade, baseada no passado. Ao contrário, vige em razão de sua função normativa, no mesmo sentido explorado por Norberto Bobbio (D’Alla Strutura alla Funzione - Nuovi Studi di Teoria di Diritto, Milano, Ed. Di Cominutá, 1997:165), ' a funşāo de assegurar a constância das expectativas, enquanto e na medida em que isso parece sensato. A fundamentação moral e ideológica do Direito seria substituida pela critica fincional.

26. Cf. a propósito Reale, 1990:110.

27. Esta garantia nada mais é senão uma manifestação do princípio da separação de poderes e do princípio da legalidade. 
14. A organização da educação no Brasil acompanha a organização federativa do País, o que significa dizer que o dever do Estado com a educação será clectivado mediante descentralização normativa e exccutiva, excrcida pela União, Estados, Distrito Federal e Municípios, de acordo com a repartição de competências, legislativas e materiais promovida pela Constituição Federal e pela Lei de Diretrizes c Bases da Educação Nacional - LDB (Lci no. 9.394, de 20//2/96).

15. Tal oferecimento far-se-á sob a égide dos princípios informadores da alividade educacional, dentre cles a garantia de padrão de qualidade do ensino, prevista no arl. 206, VII, da Constituição Federal.

16. Sendo os princípios informadores da atividade educacional decorrência de princípio fundamental, expresso telcologicamente no art. $3^{\circ}$ da Constituição Federal, sua observância ć obrigatória, cm qualquer circunstância, para qualquer sistema de ensino.

17. A mesma conclusão se evidencia sob o ângulo do federalismo cooperativo, considerando-se especialmentc o tcor do art. 211 , relativamente à exigência de organização dos sistemas de ensino, lederal, cstaduais e municipais, $\mathrm{em}$ regime de colaboração; do princípio lederativo da descentralização normativa e executiva, expresso no art. 18, que assegura aos Estados competência para exercê-la; $\mathrm{e} \mathrm{cm} \mathrm{face} \mathrm{do} \mathrm{"caput"}$ do art. 37, da Constituição Federal, que exige que a Administração Pública, direta c indireta, de qualquer dos Poderes da União, dos Estados, do Distrito Federal e dos Municípios, atenda ao princípio da eficiência.

18. O padrão de qualidade do ensino básico nas escolas públicas do Estado de São Paulo supõe professores qualificados $\mathrm{cm}$ sala de aula $\mathrm{e} \mathrm{em}$ funções de direção. É o que exige o art. 64 da Lei de Dirctrizes e Bases. Se o Conselho Nacional de Educação dispensa a autorização prévia para os cursos de especialização $\mathrm{cm}$ pedagogia, deixando de exercer sua lunção fiscalizadora com reflexos e efeitos negativos para os demais sistemas de ensino, devem estes fazê-lo.

19. Trata-se, na hipótesc, do excreício de verdadciro poder-dever para os órgãos normativos dos sistemas de ensino afectados, corolário do dever do Estado com a educação e que neste caso se sobrepõc (e extrapola) aos limites da regra do art. $9^{\circ}$, IX, da LDB, porque se cuida de princípio cducacional, de observância comum e obrigatória a todos os entes federados. O lundamento legal para altuação, nesses casos, radica nos arts. 208, VII c 18, da Constituição Federal c arts. $3^{\circ}$. IX; $9^{\circ}$. IX, e 10, I c V da LDB.

20. A autonomia dos sistemas de cnsino, de extração legal c constitucional, não se compadece com omissões no campo das competências 
cducacionais comuns. À ausência de medidas que assegurem a colaboração entre os sistemas de ensino, especialmente no que diz respeito à clelivaçĩo dos princípios informadores da atividade educacional, permite a adoção de medida corretiva, que aluem $\mathrm{cm}$ prol da mela nacional.

21. Em conclusão, entendemos que o CEE pode submeter os cursos de especialização, não sujcitos à sua jurisdição, à sua aprovação, a pedido dos interessados, para cleito do exercício das atividades de administração (diretor ou gestor de cscola), de plancjamento, inspeção, supervisão c orientação de cducação básica, jurisdicionados ao sistema cscolar do Estado de São Paulo.

22. À vista da prevalência do interesse público sobre o particular na árca da educação, não há, na possível atividade controladora do Conselho Estadual de Educação, relativamente à avaliação de qualidade de cursos de especialização em Pedagogia não sujeitos à sua jurisdição, qualquer ofensa a dircito subjetivo dos particulares envolvidos.

\section{Resposta aos Quesitos}

I. Sim. O Conselho Estadual de Educação, com fundamento no art. 208, VII da Constituição Federal c arts. $3^{\circ}$ IX; $9^{\circ}$, IX; 10, I c V; e 64 da LDB, tem competência para promover o controle prévio dos cursos de especialização $\mathrm{cm}$ Pedagogia, nos termos da Deliberação n. 09/98, independentemente de sua vinculação ao sistema federal de ensino, para exercício de atividades de administração, de plancjamento, inspeção, supervisão c orientação de educação básica, jurisdicionados ao sistema escolar do Estado de São Paulo.

2. Sim. A pedido dos interessados, poderá o Consclho Estadual de Educação proceder à avaliação dos cursos de especialização $\mathrm{cm}$ Pedagogia, não sujeitos à sua jurisdição, para cleito do exercício das atividades descritas no art. 64 da LDB.

Entendemos não ser possível excluir desta apreciação os especialistas já portadores de certificados concedidos por instituições vinculadas ao sistema federal de ensino, por ser ilegal a liberação de autorização e reconhecimento dos respectivos cursos, promovida pelo art. $6^{\circ}$, da Resolução CNE/CES n. 1/2001.

São Paulo, janciro de 2003. 